\title{
Enzyme immobilisation on electroactive nanostructured membranes (ENM): Optimised architectures for biosensing
}

\author{
Frank N. Crespilho ${ }^{a}$, M. Emilia Ghica ${ }^{\mathrm{b}}$, Carla Gouveia-Caridade ${ }^{\mathrm{b}}$, \\ Osvaldo N. Oliveira Jr. ${ }^{\mathrm{a}}$, Christopher M.A. Brett ${ }^{\mathrm{b}, *}$ \\ a Instituto de Física de São Carlos, Universidade de São Paulo, 13560-970 São Carlos-SP, Brazil \\ b Departamento de Química, Faculdade de Ciências e Tecnologia, Universidade de Coimbra, 3004-535 Coimbra, Portugal
}

\section{A R T I C L E I N F O}

\section{Article history:}

Received 9 January 2008

Received in revised form 17 April 2008

Accepted 23 April 2008

Available online $\mathrm{xxx}$

\section{Keywords:}

Layer-by-layer

Glucose oxidase

Gold nanoparticles

PAMAM dendrime

Cobalt hexacyanoferrate redox mediator

\begin{abstract}
A B S T R A C T
Electroactive nanostructured membranes have been produced by the layer-by-layer (LbL) technique, and used to make electrochemical enzyme biosensors for glucose by modification with cobalt hexacyanoferrate redox mediator and immobilisation of glucose oxidase enzyme. Indium tin oxide (ITO) glass electrodes were modified with up to three bilayers of polyamidoamine (PAMAM) dendrimers containing gold nanoparticles and poly(vinylsulfonate) (PVS). The gold nanoparticles were covered with cobalt hexacyanoferrate that functioned as a redox mediator, allowing the modified electrode to be used to detect $\mathrm{H}_{2} \mathrm{O}_{2}$, the product of the oxidase enzymatic reaction, at $0.0 \mathrm{~V} v \mathrm{~s}$. SCE. Enzyme was then immobilised by cross-linking with glutaraldehyde. Several parameters for optimisation of the glucose biosensor were investigated, including the number of deposited bilayers, the enzyme immobilisation protocol and the concentrations of immobilised enzyme and of the protein that was crosslinked with PAMAM. The latter was used to provide glucose oxidase with a friendly environment, in order to preserve its bioactivity. The optimised biosensor, with three bilayers, has high sensitivity and operational stability, with a detection limit of $6.1 \mu \mathrm{M}$ and an apparent Michaelis-Menten constant of $0.20 \mathrm{mM}$. It showed good selectivity against interferents and is suitable for glucose measurements in natural samples.
\end{abstract}

(c) 2008 Elsevier B.V. All rights reserved.

\section{Introduction}

Monolayers prepared by direct adsorption of dendrimers onto solid substrates have been proven to be highly stable and amenable to functionalisation without loss of dendrimers into solution [1]. The large surface area of dendrimers allows various functional units to be immobilised, which is important in applications such as sensors. Biosensors based on enzymes have been built which exploit the properties of dendrimers.

Dendrimer-encapsulated platinum nanoparticles have been used for layer-by-layer (LbL) glucose biosensor development on platinum electrodes [2] and on carbon nanotubes [3], and for a glutamate biosensor on carbon nanotubes [4], without redox mediator.

Yoon and Kim [5] prepared layer-by-layer films with polyamidoamine (PAMAM) dendrimer alternated with periodate oxidized glucose oxidase, on a gold substrate, and detected glucose using ferrocenemethanol in solution as diffusional electron-transfer mediator. A similar method, with the same redox mediator, was used by Yang et al. [6] but with gold nanoparticles in combina-

\footnotetext{
* Corresponding author. Tel.: +351 239835295; fax: +351 239835295.

E-mail address: brett@ci.uc.pt (C.M.A. Brett).
}

tion with the covalently attached cross-linker cysteamine instead of PAMAM. The main disadvantage of these methods is the addition of a mediator to the reaction medium.

A new method for enzymatic immobilisation was recently demonstrated by us, which uses a combination of LbL self-assembly, redox mediator electrodeposition and cross-linking [7]. It was shown how one can benefit from combining the biocatalytic properties of the enzyme with the conductivity and electrocatalytic properties of gold nanoparticles. The strategy used consists in applying a new concept in nanoarchitecture: electroactive nanostructured membranes (ENM) with ITO-PVS/PAMAM-Au LbL electrodes [8], where indium tin oxide (ITO) is the electrode substrate and PVS is poly(vinylsulfonate), which alternates with PAMAM-Au (PAMAM containing gold nanoparticles) in the bilayer structure. A redox mediator (Me) is then electrodeposited around the Au nanoparticles to form an ITO-PVS/PAMAM-Au@Me system. The redox mediators used were $\mathrm{Co}, \mathrm{Fe}, \mathrm{Ni}$ and $\mathrm{Cu}$ hexacyanoferrates. These hexacyanoferrate modified electrodes showed electrocatalytic activity towards hydrogen peroxide, demonstrating that this new approach can be used in biosensors and nanodevices, where a redox mediator is required.

The LbL assembly of oppositely charged species is a simple and powerful method to provide a suitable nanoenvironment to 
retain the biomolecular activity. Methods to build ordered enzymatic monolayer or multilayers include Langmuir-Blodgett [9], self-assembly [10], layer-by-layer electrostatic adsorption [6,11], antigen-antibody interaction [12] and surfactant films [13].

The present paper concerns several new developments with respect to the report in [7], focusing on optimising enzymatic devices and further characterising the biosensor architectures obtained with the LbL approach. Glucose oxidase (GOx) was the enzyme of choice because the catalytic properties of this enzyme are well known in the literature and because the determination of glucose concentration is important in clinical, biological and chemical samples, as well as in food processing and fermentation [14]. The preparation and characterisation of bilayer nanostructured membranes, containing gold nanoparticles, is presented. Strategies for covering the gold nanoparticles with the redox mediator cobalt hexacyanoferrate ( $\mathrm{CoHCF}$ ), and methodologies for coating by the enzyme-containing layer are investigated. Optimisation of the biosensor construction involved testing different numbers of bilayers and different ways of immobilising glucose oxidase. Sensor performance and operational stability were evaluated.

\section{Experimental}

\subsection{Reagents and buffers}

Glucose oxidase (E.C. 1.1.3.4, from Aspergillus Niger, $24 \mathrm{U} / \mathrm{mg}$ ) was acquired from Fluka. $\alpha-D(+)$-glucose, glutaraldehyde (GA) $(25 \%$, $\mathrm{v} / \mathrm{v}$ in water) and bovine serum albumin (BSA) were purchased from Sigma. Potassium hexacyanoferrate (III) $\left(\mathrm{K}_{3} \mathrm{Fe}(\mathrm{CN})_{6}\right)$ and cobalt chloride $\left(\mathrm{CoCl}_{2} \cdot 6 \mathrm{H}_{2} \mathrm{O}\right)$ were obtained from Merck. The supporting electrolyte solution for electrochemical measurements was sodium phosphate buffer saline (NaPBS) $\left(0.1 \mathrm{M} \mathrm{NaH}_{2} \mathrm{PO}_{4} / \mathrm{Na}_{2} \mathrm{HPO}_{4}+0.05 \mathrm{M}\right.$ $\mathrm{NaCl}, \mathrm{pH}$ 7.0), prepared with ultrapure water supplied by a Millipore Milli-Q nanopure system (resistivity $>18 \mathrm{M} \Omega \mathrm{cm}$ ). Experiments were performed at room temperature, $25 \pm 1{ }^{\circ} \mathrm{C}$. Polyamidoamine (PAMAM) and poly(vinylsulfonate) (PVS) were purchased from Aldrich, Germany.

\subsection{Methods and instruments}

Measurements were performed in a $15 \mathrm{~mL}$, one-compartment cell containing the ITO (indium tin oxide) modified electrode (geometric area $1.0 \mathrm{~cm}^{2}$ ) as working electrode, a platinum auxiliary electrode and a saturated calomel electrode (SCE) as reference. Voltammetric and amperometric experiments were carried out using a CV-50 W Voltammetric Analyser from Bioanalytical Systems, West Lafayette, IN, USA, controlled by BAS CV-2.1 software or a $\mu$-Autolab Type II potentiostat/galvanostat running with GPES 4.9 software (Eco Chemie, Netherlands). Electrochemical impedance measurements were carried out with a PC-controlled Solartron 1250 Frequency Response Analyser coupled to a Solartron 1286 electrochemical interface using ZPlot 2.4 software (Solartron Analytical, UK). A sinusoidal voltage perturbation of amplitude $10 \mathrm{mV}$ rms was applied in the frequency range between $65 \mathrm{kHz}$ and $0.1 \mathrm{~Hz}$ with a 10 frequency steps per decade. The $\mathrm{pH}$ measurements were performed with a CRISON 2001 micro pH-meter.

Atomic force microscopy (AFM) images were obtained with a Multimode ${ }^{\mathrm{TM}}$ Atomic Force Microscope controlled by a Digital Instruments Nanoscope E controller (Veeco Instruments, USA). The cantilevers were silicon nitride NanoProbes ${ }^{\mathrm{TM}} \mathrm{V}$-shaped, $100 \mu \mathrm{m}$ long, and with a spring constant of $0.58 \mathrm{~N} \mathrm{~m}^{-1}$. All AFM images were taken in the contact mode in air at room temperature. The contrast and brightness of the images were adjusted.

\subsection{Electrode preparation}

The working electrode was prepared from an ITO-covered glass electrode by electrostatic deposition of up to three bilayers of (PVS/PAMAM-Au) as described in detail in [7,15]. Briefly, gold metallic nanoparticles of diameter $\sim 3 \mathrm{~nm}$ stabilised by PAMAM dendrimer molecules were synthesized in aqueous solution, which was then used as cationic polyelectrolyte to build multilayers containing nanoparticles together with poly(vinylsulfonate). The sequential deposition was performed by immersing the ITO substrate alternately into the PAMAM-Au and PVS solutions for $5 \mathrm{~min}$; it was found by cyclic voltammetry and UV-vis spectroscopy that $5 \mathrm{~min}$ is sufficient for complete surface coverage by PAMAM-Au.

Following this, cobalt hexacyanoferrate was electrochemically deposited on the ITO-(PVS/PAMAM-Au $)_{n}(n=1,2$ or 3$)$ electrode and finally glucose oxidase was immobilised using the cross-linking method. Cobalt hexacyanoferrate was deposited, as described in [16], by cycling the ITO-(PVS/PAMAM-Au $)_{n}$ electrode 30 times between -0.2 and $0.9 \mathrm{~V} v$ s. SCE at a scan rate of $50 \mathrm{mV} \mathrm{s}^{-1}$ in a freshly prepared solution containing $0.5 \mathrm{mmol} \mathrm{L}^{-1} \mathrm{CoCl}_{2}, 0.25 \mathrm{mmol} \mathrm{L}^{-1}$ $\mathrm{K}_{3} \mathrm{Fe}(\mathrm{CN})_{6}$ and $0.05 \mathrm{~mol} \mathrm{~L}^{-1} \mathrm{NaCl}$ at $\mathrm{pH} 3.0$ (pH adjusted with $\mathrm{HCl}$ ).

Enzyme immobilisation was performed using the cross-linking reaction with glutaraldehyde, depicted in Scheme 1. Two enzyme immobilisation procedures were compared: dip-coating and dropcoating. GOx immobilisation by dip-coating was performed using a mixture of the enzyme with glutaraldehyde and bovine serum albumin. In the optimised procedure, the mixture contained $100 \mu \mathrm{L}$ of GA $(2.5 \%, v / v$ in water) and $240 \mu \mathrm{L}$ of enzyme solution. The latter was prepared by dissolving $20 \mathrm{mg}$ BSA and $50 \mathrm{mg}$ GOx in $1 \mathrm{~mL}$ of $0.1 \mathrm{M}$ NaPBS ( $\mathrm{pH} 7.0$ ). Electrodes previously modified with the mediator were immersed in the mixture for $2 \mathrm{~h}$, and then allowed to dry for another $2 \mathrm{~h}$ at room temperature. For drop-coating, $10 \mu \mathrm{L}$ of enzyme solution (GOx and BSA in the same proportion as used above) were placed onto the electrodes modified with the mediator. After $1 \mathrm{~h}, 10 \mu \mathrm{L}$ of GA $(2.5 \%, \mathrm{v} / \mathrm{v}$ in water) were placed on top of the electrodes and allowed to dry for $2 \mathrm{~h}$. The biosensors were first used on the day after preparation when the response was bet-
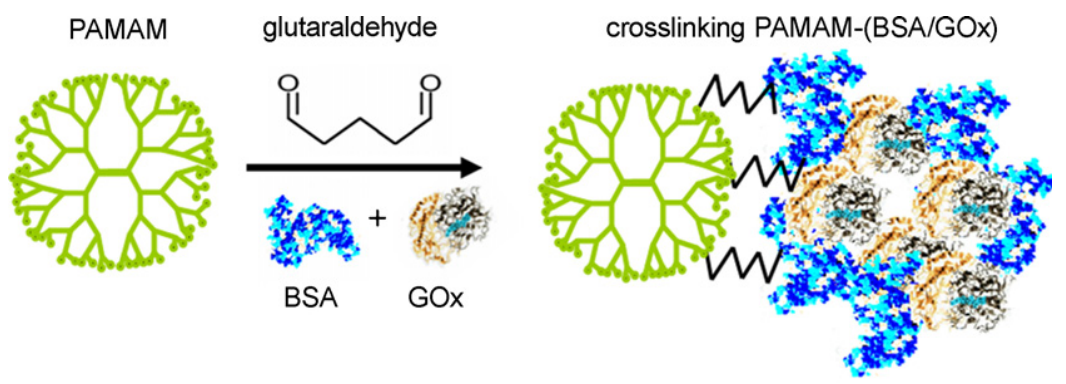

Scheme 1. Cross-linking between PAMAM and BSA/GOx system using glutaraldehyde. 
ter. When not in use, the electrodes were kept at $4{ }^{\circ} \mathrm{C}$ in phosphate buffer electrolyte, $\mathrm{pH}$ 7.0.

\section{Results and discussion}

3.1. Preparation of an electroactive nanostructured membrane (ENM) modified electrode: ITO-(PVS/PAMAM-Au) ${ }_{3} @ C o H C F$

Using PAMAM dendrimers as matrix, metallic gold nanoparticles of $\sim 3 \mathrm{~nm}$ diameter were deposited from an aqueous solution onto an ITO substrate using the LbL technique, as described in Section 2. In previous work, three bilayers of PVS/PAMAM-Au was found to be the best configuration to prepare an ITO modified electrode, since 3-bilayer PVS/PAMAM-Au LbL films were found to possess high organisation and outstanding uniformity [8].

To verify the influence of PVS/PAMAM-Au multilayers on the ITO surface morphology, a bare ITO and ITO-(PVS/PAMAM-Au) $n$ ( $n=1,2$ or 3 bilayers) systems were examined by AFM, Fig. 1. The images of ITO-(PVS/PAMAM-Au $)_{n}$ revealed a globular morphology, analogous to other LbL films [17]. Profile and roughness
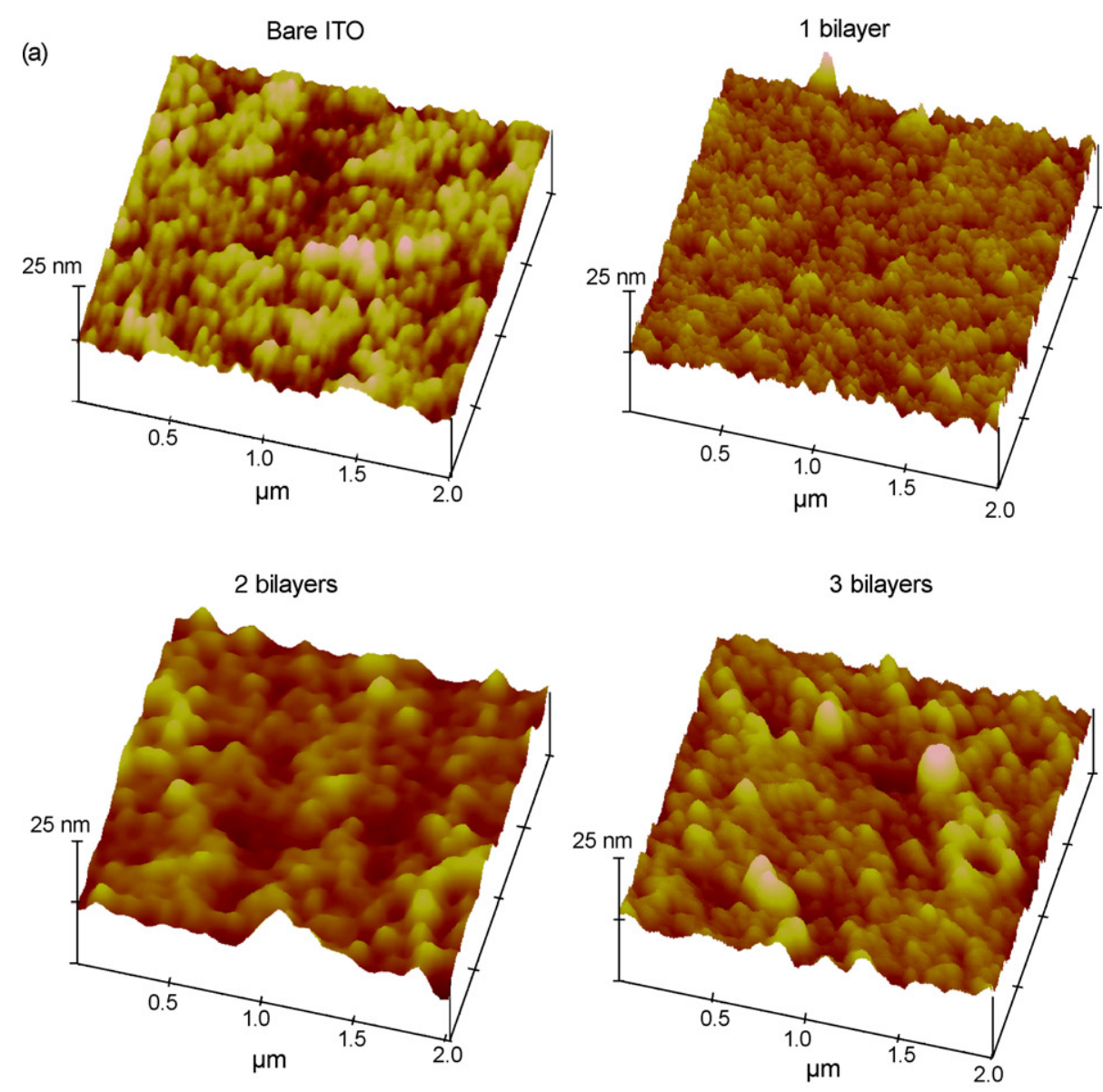

(b)
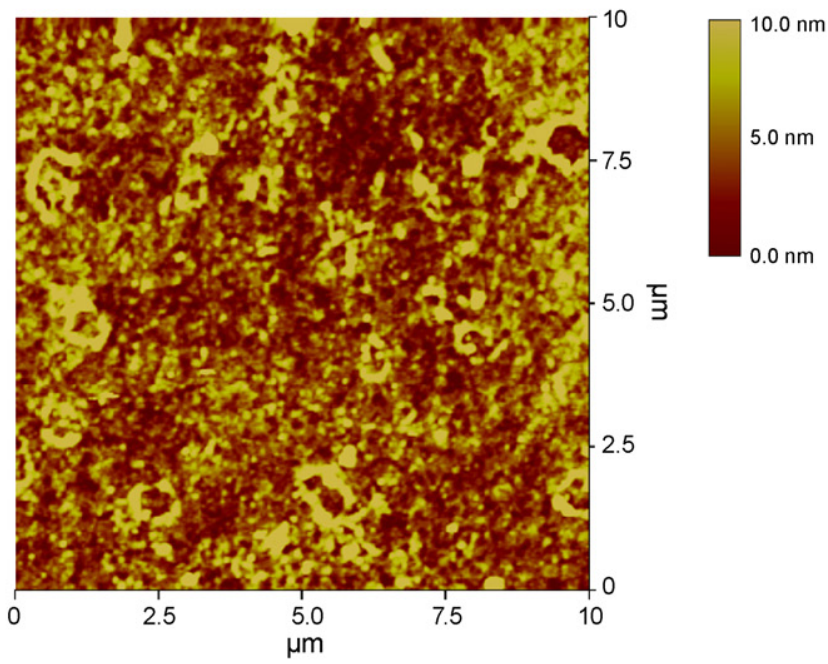

Fig. 1. (a) 3D AFM topographical images of ITO and ITO-(PVS/PAMAM-Au $)_{n}(n=1,2$, and 3). (b) AFM topographical image of ITO-(PVS/PAMAM-Au) 2 . 
analysis, carried out on images of $10 \mu \mathrm{m} \times 10 \mu \mathrm{m}$, revealed some differences in morphological parameters with the number of bilayers. The root mean square roughness, representing the standard deviation of the distribution of surface heights [18], and typically used to quantify variations in surface elevation, increases with the number of bilayers. The values were $\sim 1.93 \mathrm{~nm}$ for ITO and $\sim 2.88$, $\sim 3.31$ and $\sim 4.35 \mathrm{~nm}$ for ITO-(PVS/PAMAM-Au) $n$ with $n=1,2$ or 3 bilayers, respectively. Cross-section plots of surface morphology (not shown) reveal a uniform particle distribution with maximum height of ca. $6 \mathrm{~nm}$ for ITO, and ca. 9, 11 and $13 \mathrm{~nm}$ for the first, second and third bilayer respectively. The difference in the maximum height between the first bilayer and ITO corresponds to the diameter of one gold nanoparticle $(\sim 3 \mathrm{~nm})$. The second and third bilayers showed a uniform distribution of PAMAM nano-rings containing $\mathrm{Au}$ nanoparticles inside their cavities, which can be seen in the AFM 2D image for the second bilayer in Fig. 1b.

The last step for ITO-(PVS/PAMAM-Au) $)_{3} @$ CoHCF build-up was to use the system ITO-(PVS/PAMAM-Au) $)_{3}$ as working electrode to electrochemically modify the PAMAM-Au surface. We previously showed that ITO-(PVS/PAMAM-Au) ${ }_{3}$ structures are suitable for biosensors and electrocatalysis owing to their low capacitive and high Faradaic currents associated with low ohmic drop [8]. Electrodeposition by potential cycling of cobalt hexacyanoferrate onto ITO-(PVS/PAMAM-Au) $)_{3}$ electrodes was carried out according to the optimised conditions in previous work $[7,16]$. As shown in Fig. 2a, CoHCF was successfully deposited onto ITO-(PVS/PAMAM-Au) 3 electrodes by potential cycling, with the cathodic and anodic peak currents increasing linearly with the number of cycles. The deposited mediator was characterised by cyclic voltammetry in $0.1 \mathrm{M} \mathrm{NaPBS}$ ( $\mathrm{pH} 7.0$ ) supporting electrolyte, the anodic and cathodic peak currents being a linear function of the square root of the scan rate, as shown in Fig. 2b. Therefore, the electrochemical process is controlled by diffusion of the counter ion.

In [8] and by comparing electrochemical impedance spectra of different electrodeposited metal hexacyanoferrate mediators, it was demonstrated that the charge-transfer at ITO-(PVS/PAMAM$\mathrm{Au})_{3} @ M e$ electrodes is faster than at ITO-(PVS/PAMAM-Au) $)_{3}$, and the charge-transfer resistance using CoHCF is lower than for other hexacyanoferrates (e.g. CuHCF, FeHCF and NiHCF). In general terms, the spectra collected after mediator deposition differ from those of ITO-(PVS/PAMAM-Au) $)_{3}$ electrodes with the mediator in solution. The strategy used here to study diffusion and charge-transport mechanisms was to analyse the impedance at high frequencies for ITO-(PVS/PAMAM-Au) $)_{3}$ electrodes before and after immobilisation of $\mathrm{CoHCF}$ redox mediator. After cycling to immobilise the redox mediator, the spectra of the new system containing Au@CoHCF were recorded. The results obtained at the open circuit potential are shown in the complex plane plots of Fig. 3a, with a semicircle at high frequencies in the complex plane plot after redox mediator immobilisation. The relatively small diameter is evidence of fast charge-transport, and the value of the charge-transfer resistance can also be related to the degree of coverage of the gold nanoparticles by $\mathrm{CoHCF}$, assuming that electron-transfer reactions occur at CoHCF sites inside the LbL film. The spectra for the ITO-(PVS/PAMAM-Au $)_{3}$ system both with and without CoHCF also exhibit very reproducible near-vertical parallel lines at low frequencies, a typical finite-diffusion behaviour observed for electrodes covered by conducting films.

The ITO-(PVS/PAMAM-Au) $)_{3} @ \mathrm{CoHCF}$ electrode was used as working electrode for amperometric measurements of $\mathrm{H}_{2} \mathrm{O}_{2}$ in $0.1 \mathrm{M}$ NaPBS ( $\mathrm{pH} 7.0$ ), at an applied potential of $0.0 \mathrm{~V}$ vs. SCE. The current changed cathodically with the injection of fifteen aliquots of $\mathrm{H}_{2} \mathrm{O}_{2}$ stock solution to the buffer, with a good linearity between 20 and $100 \mu \mathrm{M}$ (data not shown); the total analysis time was half
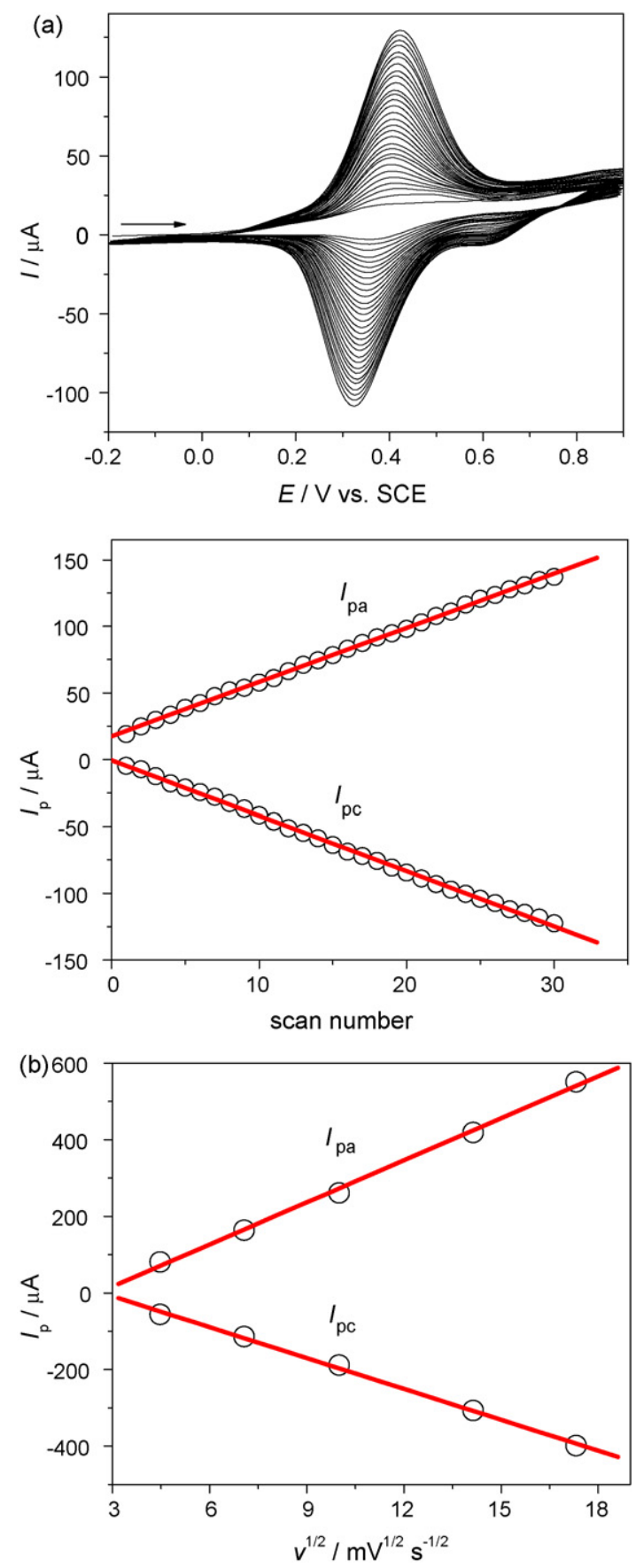

Fig. 2. (a) Cyclic voltammograms showing continuous growth of $\mathrm{CoHCF}$ on ITO(PVS/PAMAM-Au $)_{3}$ electrodes and dependence of anodic and cathodic peak currents on the number of cycles. (b) Dependence of anodic and cathodic peak currents on the square root of scan rate for the ITO-(PVS/PAMAM-Au) $)_{3} @ \mathrm{CoHCF}$ electrode in $0.1 \mathrm{M}$ NaPBS (pH 7.0).

an hour. The detection limit (three times the signal-to-noise ratio) was $5.7 \mu \mathrm{M}$. The corresponding regression equation of the linear plot was $I / \mathrm{nA}=3.44-237.55 c$, where $c$ is the $\mathrm{H}_{2} \mathrm{O}_{2}$ concentration in $\mu \mathrm{M}$, with a correlation coefficient $R=0.9989$. The stability of the CoHCF mediator on the ITO-(PVS/PAMAM-Au) $)_{3}$ electrode was studied by performing successive calibration curves at the same electrode leading to a decrease of up to $50 \%$, probably due either to some damage of the mediator film caused by the peroxide or by leaching of the mediator. However, this loss of sensitivity should not affect the operation of the enzyme biosensor since the media- 
(a)
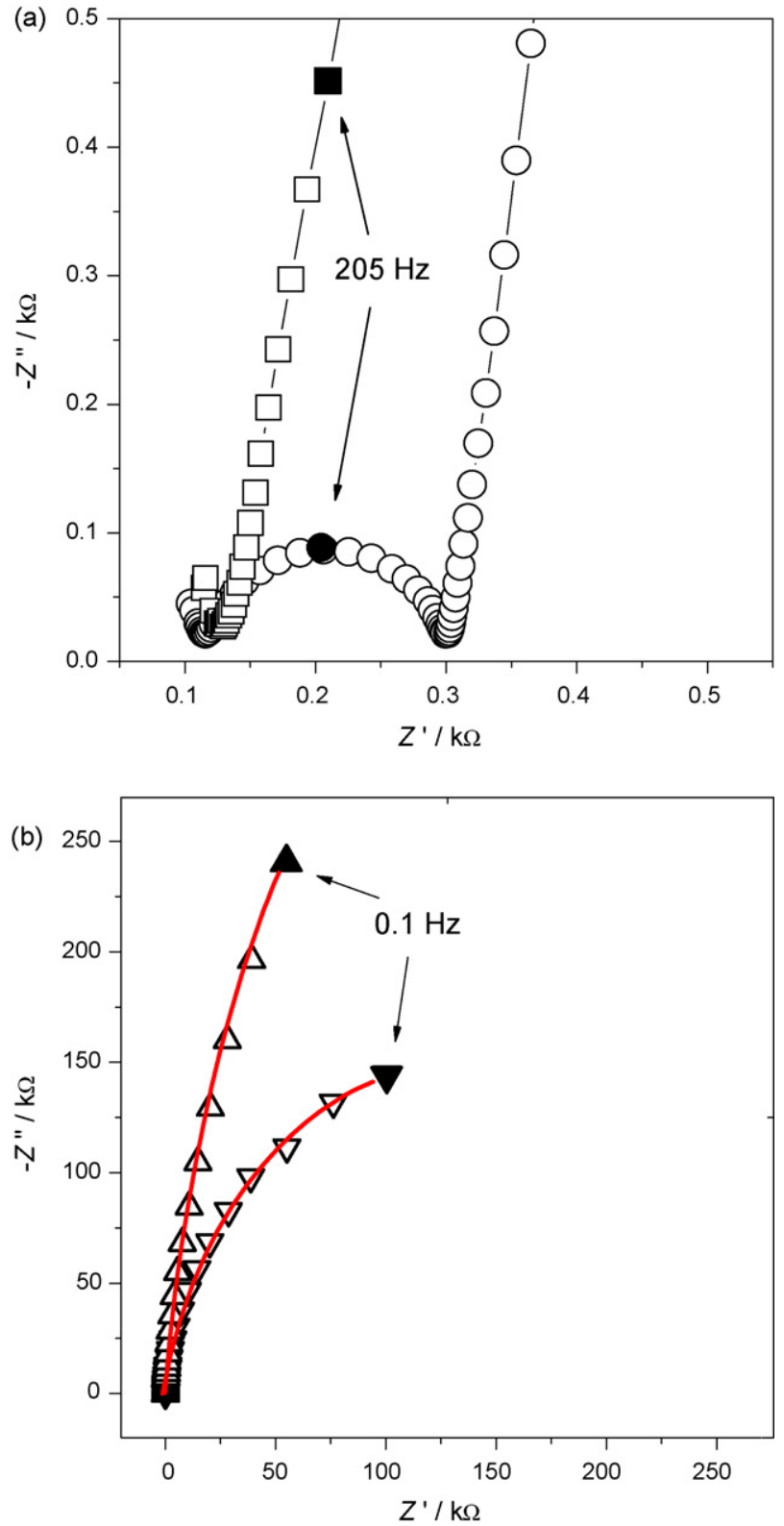

Fig. 3. Complex plane impedance spectra for electrode at $0.0 \mathrm{~V}$ vs. SCE in $0.1 \mathrm{M}$ NaPBS, pH 7.0 of (a) ITO-(PVS/PAMAM-Au $)_{3}$ electrode before (- $\left.\square-\right)$ and after (- $\bigcirc-$ CoHCF electrodeposition); (b) ITO-(PVS/PAMAM-Au) $)_{3} @ \mathrm{CoHCF}-G O x$ in the absence $\left(-\Delta^{-}\right)$and presence $(-\nabla-)$ of glucose. Frequency range: $65 \mathrm{kHz}$ to $0.1 \mathrm{~Hz}$.

tor is trapped under the enzyme layer and the amount of peroxide is less, as will be demonstrated below.

\subsection{Enzyme immobilisation onto ITO-(PVS/PAMAM-Au) $)_{3} @ C o H C F$ electrode using dip-coating and drop-coating procedure}

Enzyme immobilisation onto ITO-(PVS/PAMAM-Au) $)_{3} @ \mathrm{CoHCF}$ was carried out by assembling GOx using dip-coating or dropcoating, as described Section 2. The resulting architecture is ITO-(PVS/PAMAM-Au) $)_{3} @$ CoHCF-GOx electrode. The response to glucose was evaluated in amperometric mode at $0.0 \mathrm{~V}$. vs. SCE. Detection at this low potential represents a significant improvement for the determination of glucose with respect to previous glucose enzymatic devices using dendrimers, in which the potentials (vs. SCE) used were 0.67 V [19], 0.55 V [20] and 0.25 V [6].

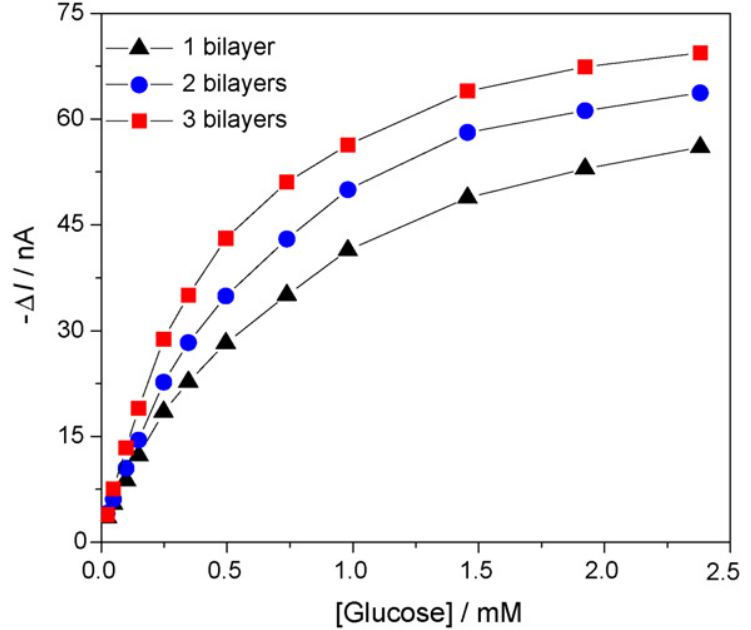

Fig. 4. Glucose response curves at ITO-(PVS/PAMAM-Au)@CoHCF-GOx electrode prepared with $20 \mathrm{mg} \mathrm{mL}^{-1} \mathrm{BSA}, 50 \mathrm{mg} \mathrm{mL}^{-1} \mathrm{GOx}$ and 2.5\% GA by drop-coating using ( $\mathbf{\text { ) }} 1$ bilayer; ( $) 2$ bilayers and ( $\square$ ) 3 bilayers of (PVS/PAMAM-Au) in $0.1 \mathrm{M} \mathrm{NaPBS}$ ( $\mathrm{pH}$ 7.0). Applied potential 0.0 V vs. SCE.

Several parameters were studied to optimise the biosensor response. It was first investigated whether the number of bilayers, up to three, deposited on the ITO electrode influenced the results. In previous papers [15,21], it was found that the electrodes with best performance were prepared with up to 3 bilayers, and additional bilayers led to no improvement in response. Therefore, electrodes with one, two and three bilayers of (PVS/PAMAM-Au) were prepared, $\mathrm{CoHCF}$ mediator was electrodeposited and then the enzyme was immobilised by dip-coating or drop-coating of the enzyme solution (see Section 2 for enzyme solution preparation). Fig. 4 shows a better glucose response curve for a drop-coated electrode with three bilayers of (PVS/PAMAM-Au), in comparison to that with one or two bilayers. Similar results were obtained with the electrode prepared by dip-coating of enzyme solution (not shown).

Secondly, the response to glucose following enzyme immobilisation by dip-coating or by drop-coating was compared, see Fig. 5 . The drop-coating method proved more suitable than dip-coating for enzyme immobilisation, leading to a higher response by about $30 \%$ and a detection limit up to three times lower comparing with that obtained by the dip-coating technique. The reason for this

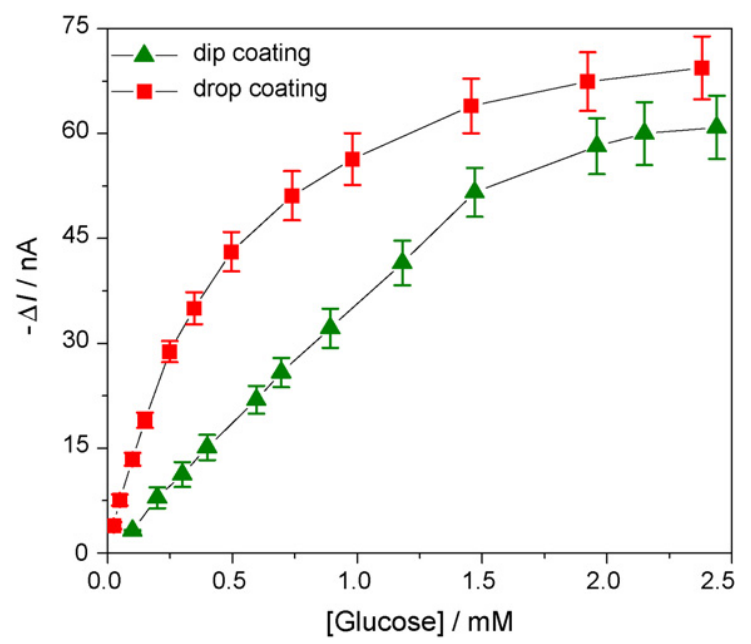

Fig. 5. Glucose response curves at ITO-(PVS/PAMAM-Au) ${ }_{3} @ \mathrm{CoHCF}-\mathrm{GOx}$ electrode obtained by $(\boldsymbol{\Lambda})$ dip-coating and $(\square)$ drop-coating in $0.1 \mathrm{M} \mathrm{NaPBS}$ (pH 7.0). Applied potential $0.0 \mathrm{~V} v s$. SCE. 

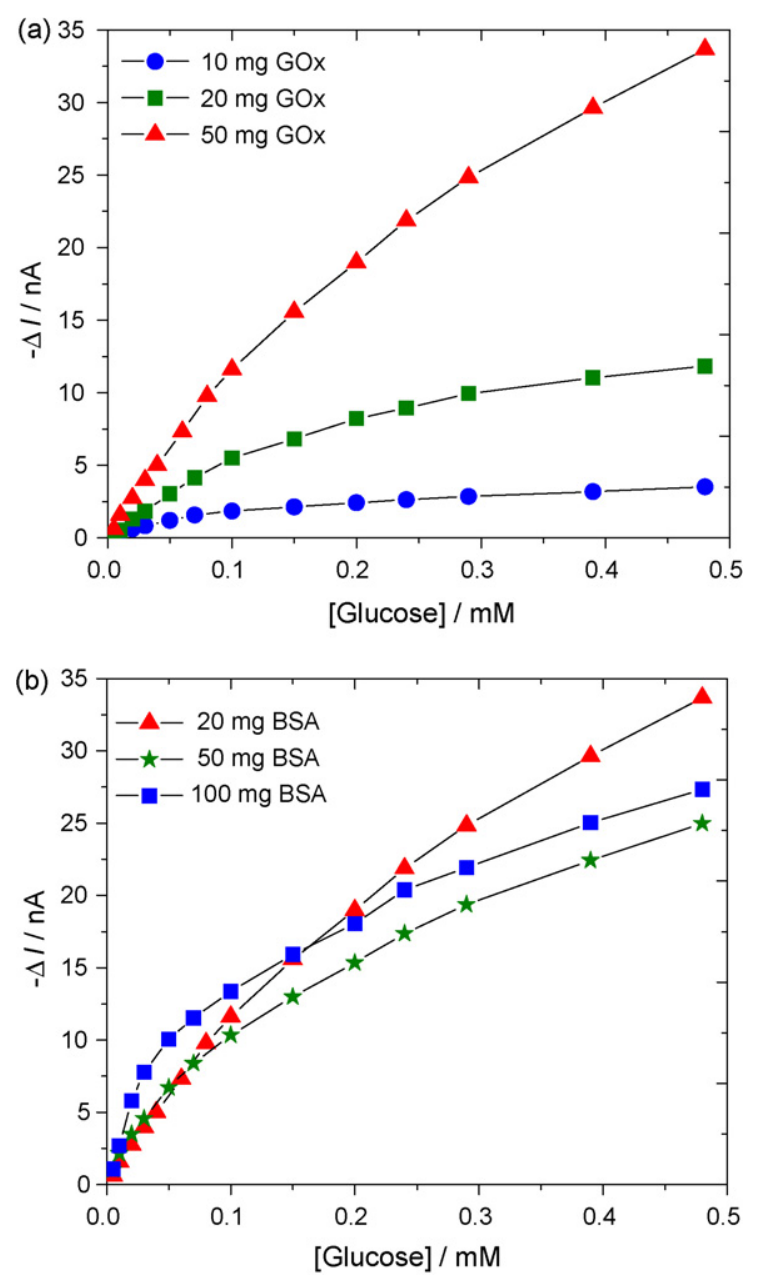

Fig. 6. Glucose response curves at ITO-(PVS/PAMAM-Au) $)_{3} @ \mathrm{CoHCF}-\mathrm{GOx}$ electrode in $0.1 \mathrm{M} \mathrm{NaPBS}(\mathrm{pH} 7.0$ ) at $0.0 \mathrm{~V} v$ s. SCE using drop-coating with $2.5 \% \mathrm{GA}$ and (a) $20 \mathrm{mg} \mathrm{mL}^{-1}$ BSA and different GOx concentrations: (1) 10 ; () 20 ; (A ) $50 \mathrm{mg} \mathrm{mL}^{-1}$. (b) $50 \mathrm{mg} \mathrm{mL}^{-1}$ GOx and different BSA concentrations: (A ) 20; ( $\star$ ) 50; ( $100 \mathrm{mg} \mathrm{mL}^{-1}$.

difference may be due to the preparation method. In the case of drop-coating, an aliquot of the enzyme solution with BSA was placed on the mediator-modified electrode and left to dry for $1 \mathrm{~h}$, the time required for the enzyme to bind to the dendrimer amino group. Then, glutaraldehyde was placed on top of the enzyme to perform cross-linking. It is likely that a more robust biosensor is achieved when using this technique by permitting stronger binding between enzyme and dendrimer, before cross-linking by glutaraldehyde, leading to better stability and sensitivity. Moreover, the amount of immobilised enzyme is better controlled by drop-coating.

Finally, the influence of the concentration of the enzyme and BSA on the electrode response was studied by keeping the concentration of BSA constant and varying the concentration of GOx, and vice versa. Fig. 6a shows a higher glucose response for increasing enzyme concentrations in the range from 10 to $50 \mathrm{mg} \mathrm{mL}^{-1}$; it is likely that the response could be further increased with larger amounts of enzyme, but this would increase the cost of the biosensor. With the GOx concentration fixed at $50 \mathrm{mg} \mathrm{mL}^{-1}$, an increase of sensitivity was observed for increasing BSA concentrations, but this was accompanied by a decrease of the linear range of the biosensor, as shown in Fig. 6b. Therefore, to study the effect of the concentration of glutaraldehyde, $50 \mathrm{mg} \mathrm{mL}^{-1}$ of GOx and $20 \mathrm{mg} \mathrm{mL}^{-1}$ of BSA were employed. The response with $25 \% \mathrm{GA}$ was a factor of five lower than that for $2.5 \% \mathrm{GA}$, which might be due to enzyme deactivation during cross-linking.

\subsection{Analytical characteristics of the

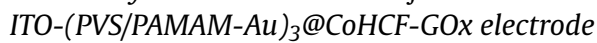

The optimised electrode system, i.e. ITO-(PVS/PAMAM$\mathrm{Au})_{3} @ \mathrm{CoHCF}-\mathrm{GOx}$ with GOx immobilised by the drop-coating method using a solution of $50 \mathrm{mg} \mathrm{mL}^{-1}$ of GOx, $20 \mathrm{mg} \mathrm{mL}^{-1}$ of BSA and $2.5 \% \mathrm{GA}$, was used to obtain the full analytical characteristics of the biosensor.

The response to glucose measured in $0.1 \mathrm{M} \mathrm{NaPBS}(\mathrm{pH} 7.0)$ at $0.0 \mathrm{~V} v s$. SCE was found to be linear up to $250 \mu \mathrm{M}$ glucose with a sensitivity of $111 \mathrm{nA} \mathrm{mM}^{-1}$, correlation coefficient $R=0.9998$ and a detection limit (three times signal-to-noise ratio) of $6.1 \mu \mathrm{M}$. The glucose sensor described in [16], which used a CoHCF mediator layer on a carbon film substrate covered by the enzyme layer, had a detection limit of $1.9 \mu \mathrm{M}$, lower by a factor of three, and a smaller linear range up to $30 \mu \mathrm{M}$. The sensor described here shows a larger linear range, which may be advantageous in the analysis of some natural samples such as sweet wines, in that less sample dilution is required.

Another important characteristic of this electrode, which can be obtained from electrochemical impedance data, see Fig. 3b, is the lower charge-transfer resistance for hydrogen peroxide reduction when glucose is present in the electrolyte solution. This supports the hypothesis that the ITO-(PVS/PAMAM-Au) ${ }_{3} @ \mathrm{CoHCF}-\mathrm{GOx}$ electrode promotes easier electron-transfer reaction, as mentioned above. The apparent Michaelis-Menten constant $\left(K_{\mathrm{M}}{ }^{\mathrm{app}}\right)$ was determined from the Lineweaver-Burk plot. The value of $K_{\mathrm{M}}$ app obtained was $0.20 \mathrm{mM}$, which is similar to other values reported in the literature [20] and lower than the value for the enzyme in solution. This might be explained by the fact that in the case of immobilised enzymes the overall reaction rate is not controlled just by the diffusion of the substrate, some other processes occurring in the same time leading to a slower kinetic rate.

The operational stability was tested by measuring the response to a glucose concentration of $0.74 \mathrm{mM}$ during 20 measurements, after which the current response dropped by $30 \%$. This loss of stability after consecutive measurements can be due to the interaction of the hydrogen peroxide produced in the enzymatic reaction with the mediator, which can damage the CoHCF film. The storage stability was good when the electrodes were kept at $4{ }^{\circ} \mathrm{C}$ in phosphate buffer solution. After 1 month of storage the biosensor still maintained $65 \%$ of its initial response.

The selectivity of the biosensor was assessed by checking the influence of interferents such as chemical species normally present in wines. In these experiments, a concentration of $0.30 \mathrm{mM}$ glucose and $0.60 \mathrm{mM}$ interferent was used. From the interferents studied, viz. fructose, ethanol, acetic acid, ascorbic acid, citric acid, lactic acid, malic acid, oxalic acid and tartaric acid, only ascorbic acid was detected at $0.0 \mathrm{~V} v$ s. SCE. In order to reduce the ascorbic acid interference, experiments were performed in which glucose was measured at two other potentials, -0.050 and $-0.180 \mathrm{~V}$ vs. SCE (not shown). The response to ascorbic acid then decreased, and at $-0.180 \mathrm{~V} v \mathrm{~s}$. SCE the signal was only $8.6 \%$ of that at $0.0 \mathrm{~V}$. The response to glucose also showed some decrease, but by much less, to $78.3 \%$. Since the response to glucose normally increases when applying more negative potentials (verified in independent measurements, data not shown) this decrease in the glucose response might be due to some loss of stability during consecutive measurements, as stated before. However, at $-0.180 \mathrm{~V} v s$. SCE it is possible to measure glucose without interferences from the above-mentioned compounds, and the response to ascorbic acid, present in the form of ascorbate, at the value of $\mathrm{pH}$ used in the experiments, is reduced 
much more. Taking into account the fact that the concentration of ascorbic acid in natural samples, such as wine, is much lower than that of glucose, it should therefore not represent any interference in the determination of glucose. If necessary, an outer layer of a cation exchange polymer, such as Nafion, can be added to the biosensor assembly in order to exclude anions, such as ascorbate, for measurements in complex natural samples.

\section{Conclusions}

A novel glucose biosensor has been developed using ITOcovered glass electrodes modified with three bilayers of (PVS/PAMAM-Au) self-assembly as supporting electrode with cobalt hexacyanoferrate mediator and glucose oxidase enzyme. Electrodeposition of cobalt hexacyanoferrate on the gold nanoparticles led to successful determination of hydrogen peroxide at lower potentials where other compounds had less electroactivity. After optimising the immobilisation of glucose oxidase on the modified electrode assembly, glucose was measured amperometrically at $0.0 \mathrm{~V} v s$. SCE; the biosensor showed a linear response up to $250 \mu \mathrm{M}$ glucose with a detection limit $(3 \sigma)$ of $6.1 \mu \mathrm{M}$. The biosensor had a good operational and storage stability, and was tested successfully against interferences normally present in wines. This work opens up excellent future perspectives for the development of electrochemical biosensors constructed using such a layer-by-layer modification strategy.

\section{Acknowledgements}

Financial support from FAPESP, CAPES, CNPq, IMMP/MCT (Brazil), from European Project HPRN-CT-2002-00186, and from Fundação para a Ciência e Tecnologia (FCT) Portugal, project
PTDC/QUI/65255/2006, POCI 2010 (co-financed by the European Community Fund FEDER), PhD grants SFRH/BD/14014/2003 - MEG and SFRH/BD/18659/2004 - CGC, and ICEMS (Research Unit 103), is gratefully acknowledged.

\section{References}

[1] W.M. Lackowski, J.K. Campbell, G. Edwards, V. Chechik, R.M. Crooks, Langmuir 15 (1999) 7632

[2] Y. Zhu, H. Zhu, X. Yang, L. Xu, C. Li, Electroanalysis 19 (2007) 698.

[3] L. Xu, Y. Zhu, L. Tang, X. Yang, C. Li, Electroanalysis 19 (2007) 717.

[4] L. Tang, Y. Zhu, L. Xu, X. Yang, C. Li, Talanta 73 (2007) 438.

[5] H.C. Yoon, H.S. Kim, Anal. Chem. 72 (2000) 922.

[6] W. Yang, J. Wang, S. Zhao, Y. Sun, C. Sun, Electrochem. Commun. 8 (2006) 665.

[7] F.N. Crespilho, M.E. Ghica, M. Florescu, F.C. Nart, O.N. Oliveira Jr., C.M.A. Brett, Electrochem. Commun. 8 (2006) 1665.

[8] F.N. Crespilho, M.E. Ghica, V. Zucolotto, F.C. Nart, O.N. Oliveira Jr., C.M.A. Brett, Electroanalysis 19 (2007) 805.

[9] S.K. Sharma, R. Singhal, B.D. Malhotra, N. Sehgal, A. Kumar, Biotechnol. Lett. 26 (2004) 645.

[10] S. Campuzano, R. Galvez, M. Pedrero, F.J.M. de Villena, J.M. Pingarron, Anal. Bioanal. Chem. 377 (2003) 600.

[11] G. Liu, Y. Lin, Electrochem. Commun. 8 (2006) 251.

[12] R. Blonder, E. Katz, Y. Cohen, N. Itzhak, A. Riklin, I. Willner, Anal. Chem. 68 (1996) 3151.

[13] J.F. Rusling, Acc. Chem. Res. 31 (1998) 363.

[14] S. Liu, H. Ju, Biosens. Bioelectron. 19 (2003) 177.

[15] F.N. Crespilho, V.Zucolotto, C.M.A. Brett, O.N. Oliveira Jr., F.C. Nart, J. Phys. Chem. B 110 (2006) 17478 .

[16] M. Florescu, C.M.A. Brett, Anal. Lett. 37 (2004) 871

[17] Z.-M. Liu, Y. Yang, H. Wang, Y.-L. Liu, G.-L. Shen, R.-Q. Yu, Sens. Actuators B 106 (2005) 394

[18] E.S. Gadelmawla, M.M. Koura, T.M.A. Maksoud, I.M. Elewa, H.H. Soliman, J. Mater. Process. Technol. 123 (2002) 133.

[19] M. Snejdarkova, L. Svoboda, V. Gajdos, T. Hianik, J. Mater. Sci. Mater. Med. 12 (2001) 1079.

[20] B. Alonso, P.G. Armada, J. Losada, I. Cuadrado, B. Gonzalez, C.M. Casado, Biosens. Bioelectron. 19 (2004) 1617.

[21] F.N. Crespilho, F. Huguenin, V. Zucolotto, P. Olivi, F.C. Nart, O.N. Oliveira Jr., Electrochem. Commun. 8 (2006) 348. 